Ann. Zootech., I966, (I), 85-88.

\title{
EFFETS COMBINÉS DE DIFFÉRENTS PARAMÈTRES DE FONCTIONNEMENT DE LA MACHINE A TRAIRE
}

\author{
J. LABUSSIÈRE: \\ Avec la collaboration technique de J. F. Combaud \\ Laboratoire de Physiologie de la Lactation, \\ Centre national de Recherches zootechniques, 78-Jouy-en-Josas
}

\section{INTRODUC'TION}

Au cours d'une mise au point bibliographique récente (LABIssière et RICHARD, I965), nous avons rapporté l'influence favorable sur la vitesse de traite, de l'augmentation séparée, du niveau de vide, du rapport ou de la vitesse de pulsation.

Il paraissait donc logique d'essayer de conjuguer au sein d'une même machine les effets bénéfiques de ces 3 paramètres, d'autant plus que les conséquences de ceux-ci sur la production laitière, le niveau d'égouttage et l'état sanitaire de la mamelle paraissent encore très discutables.

L'objet de cette note est de résumer les résultats de tels essais.

\section{MATÉRIEL ET MÉTHODES}

\section{A - Caractéristiques des deux machines à traire}

Nous avons comparé 2 types de machine à traire de marque Alfa-Laval dont les caractéristiques étaient les suivantes :

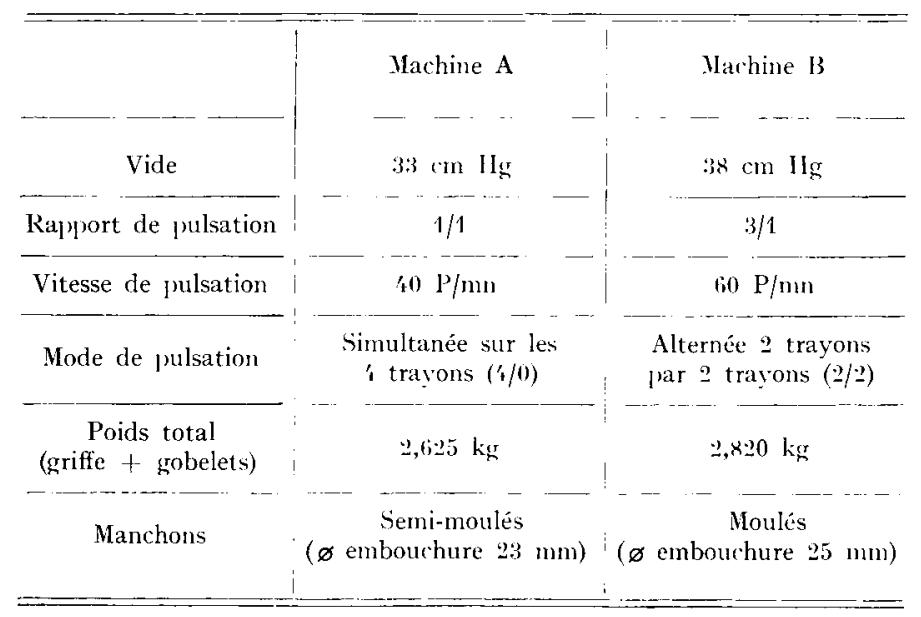




\section{B - Technique de traite}

- heures de traite : le matin à 6 heures, 1'après-midi à I $6 \mathrm{~h} 30$;

- préparation de la mamelle :

massage pendant $40 \mathrm{~s}$ avec un linge humide trempé dans de $1^{\prime}$ eau à $45^{\circ}$; pose des gobelets $30 \mathrm{~s}$ après la fin du massage.

- égouttage-machine : il débute lorsque le débit de lait devient inférieur à Ioo $g$ par fraction de $\mathbf{I} 5$ secondes.

\section{$\mathrm{C}$ - Mesures effectuées et protocole expérimental}

Les essais ont porté sur Io vaches françaises, Frisonne, Pie-Noire, divisées en 2 lots :

Lot I : 4 animaux en Ire lactation ( $2^{\mathrm{e}}$ mois), I en $5^{\mathrm{e}}\left(7^{\mathrm{e}}\right.$ mois) ;

Lot $2: 4$ animaux en $I^{\text {re }}$ lactation ( $2^{\mathrm{e}}$ mois), I en $5^{\mathrm{e}}$ ( $6^{\mathrm{e}}$ mois).

Ils ont duré 24 jours, chaque lot subissant alternativement pendant 3 jours la machine A, puis pendant 3 jours, la machine B. Toutes les vaches ont donc été contrôlées un nombre égal de fois avec les 2 systèmes et à chaque traite les paramètres suivants ont été mesurés :

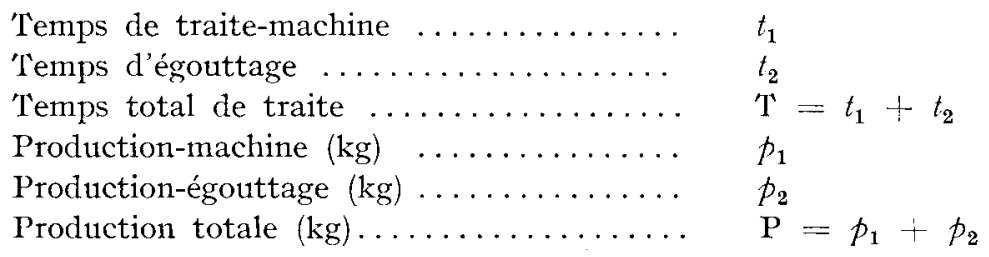

Par ailleurs, pendant les 2 semaines qui ont suivi cette expérience, nous avons comparé à l'aide du test CM'T, l'état sanitaire des mamelles soumises aux 2 systèmes de traite.

\section{RÉSULTATS E'T DISCUSSION}

Ils sont regroupés au tableau $n^{\circ} \mathrm{I}$.

Avec la machine $B$, la production laitière semble légèrement augmentée et l'égouttage-machine a tendance à dimiuner. La différence n'est toutefois pas significative, mais il est possible qu'au cours d'expériences de plus longue durée, un effet à long terme sur la sécrétion laitière puisse être mis en évidence. Par contre, le temps de traite-machine et le temps de traite total sont très significativement diminués (respectivement I 9,3 p. Ioo et I 8,9 p. Ioo en moyenne par jour). A cet égard, la réaction est très variable d'un animal à l'autre (de $4 \mathrm{p}$. Ioo à $30 \mathrm{p}$. IOo), l'efiet étant plus important chez les animaux difficiles à traire. Il est délicat d'attribuer au manchon, au niveau de vide, au rapport ou à la vitesse de pulsation, le mérite principal de cette 


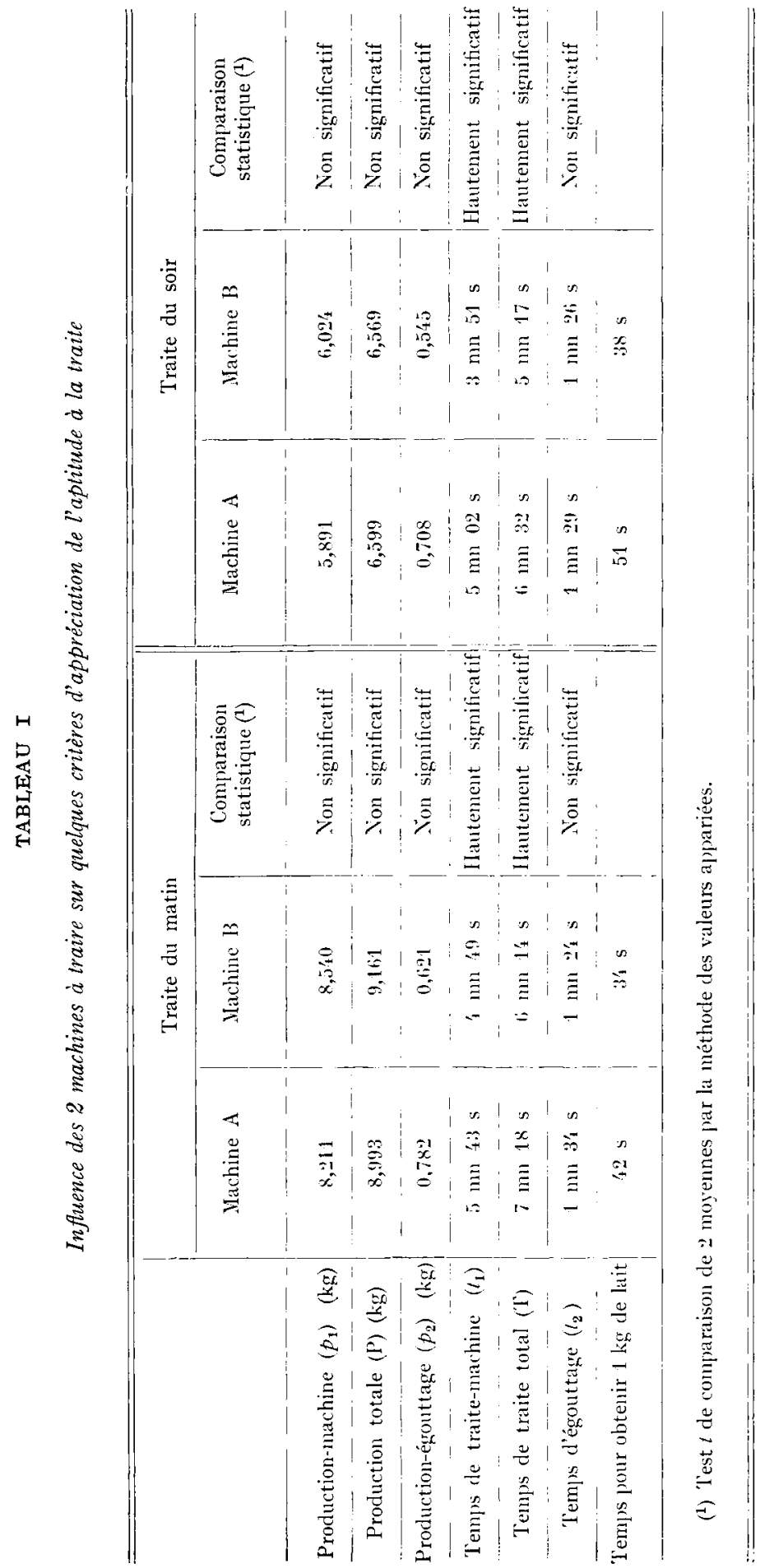


efficacité. Chacun de ces paramètres pris séparément a certainement une action bénéfique (LABUSSIÈRE et RICHARD, I965), mais leur coordination au sein d'un même système assure probablement une harmonie encore accrue entre la mamelle et la machine.

L'utilisation de l'un ou l'autre système n'a pas entraîné de modifications du test CM'T.

Rę̧u pour publication en mars 1966.

\section{RÉFÉRENCES BIBLIOGRAPHIQUES}

LABUSSiÉre J., Richard P., 1965. La traite mécanique. Aspects anatomiques, physiologiques et technologiques. Mise au point bibliographique. Ann. Zoolech., 14, $63-126$. 